\title{
Varioliform Gastritis after Ibuprofen Poisoning
}

\author{
Atipo Ibara Blaise Irénée 1,2, Mongo Onkouo Arnaud1,2, Ahoui Apendi Clausinaa, \\ Atipo Ibara Ollandzobo Lucie Charlotte ${ }^{1,3}$, Mimiesse Monamou Jile Florient ${ }^{1,2}$, \\ Itoua-Ngaporo Akoa Ngala², Deby Gassaye ${ }^{1,2}$, Bossali Firmin1, Ibara Jean-Rosaire ${ }^{1,2}$ \\ ${ }^{1}$ Faculty of Medical Sciences, Marien Ngouabi University, Brazzaville, Congo \\ ${ }^{2}$ Department of Gastroenterology and Internal Medicine, Brazzaville University Hospital Centre, Brazzaville, Congo \\ ${ }^{3}$ Paediatric Service, Brazzaville University Hospital Centre, Brazzaville, Congo \\ Email: batipoibara@yahoo.fr, b.atipo-ibara@laposte.net
}

How to cite this paper: Irénée, A.I.B., Arnaud, M.O., Clausina, A.A., Charlotte, A.I.O.L., Florient, M.M.J., Ngala, I.-N.A., Gassaye, D., Firmin, B. and Jean-Rosaire, I. (2018) Varioliform Gastritis after Ibuprofen Poisoning. Open Journal of Gastroenterology, 8, 103-106.

https://doi.org/10.4236/ojgas.2018.83011

Received: January 10, 2018

Accepted: March 26, 2018

Published: March 29, 2018

Copyright $\odot 2018$ by authors and Scientific Research Publishing Inc. This work is licensed under the Creative Commons Attribution International License (CC BY 4.0).

http://creativecommons.org/licenses/by/4.0/

\begin{abstract}
Diffuse varioliform gastritis is a rare attack of the gastric mucosa occurring mostly on atopic ground. This report is based on the observation of a 16-year-old girl with diffuse varioliform gastritis discovered after an internal medical examination via endoscope after attempting a suicidal act by overdosing herself with Ibuprofen. After the medical examination of the patient. Despite the quantity of ingested ibuprofen and presence of Helicobacter pylori on the biopsie, the particularity of this study is that there is no exudative lesion of the gastric mucosa. With hélicobacter pylori eradication evolution was favorable.
\end{abstract}

\section{Keywords}

Varioliform Gastritis, Ibuprofen, Teenager

\section{Introduction}

Diffuse Varioliformis gastritis is a rare form of inflammation of the gastric mucosa [1] [2]. It does not have specific clinical manifestations but it does have multiple factors and sometimes entangled. Our observation is based on the medical examination of a teenage girl with a gastropathy varioliformis after a massive ingestion of ibuprofen attempting to end her own life following a family dispute.

\section{Observation}

A teenager girl of 16-year-old who was examined for epigastric pains with cramping without radiation, but combined with severe vomiting after taking thirty (30) tablets, or $1500 \mathrm{mg}$ of ibuprofen for a suicidal purposes following a 
family dispute.

However, she reported having recurrent epigastric unexplored epigastric pains and no cutanous allergic reaction to nickel. She had no food allergy, bronchial ashtma, allergic rhinitis or psychiatric illness.

On our medical examination, she did have a good general health condition, a good hemodynamic condition, the abdomen was supple, sensitive to the epigastrium, without any signs of peritoneal irritation, neurological, cardiovascular, pulmonary and lympho-ganglionic examinations were normal, as well as pelvic touches.

Standard biological examinations were also normal. The assay of serum Ig and parasitologist examination of stools were also normal.

High gastrointestinal endoscopy demonstrated a nodular macro aspect of the entire gastric mucosa, with no loss of substance performing a diffuse varioliformis aspect.

Histological analysis of biopsy parts after staining the hématosine eosin showed fragments of exulcérative gastric mucosa. The surface coating had a good maturation. The glands were normocriniquesed in a chorion with two lymphoid follicles and a diffuse inflammatory infiltrate made of lymphocytes and plasma and quite numerous neutrophils. Colonies of Helicobacter pylori were noted. These lesions corresponded to an exudative gastritis on chronic, non-atrophic follicular gastritis without metaplasia or dysplasia.

The proposed therapeutic treatment consisted of administrating the Esomeprazole $40 \mathrm{mg}$ twice per day combined with amoxicillin $500 \mathrm{mg}$ twice per day and also the Clarythromicine $500 \mathrm{mg}$ twice per day for the course of 14 days followed with some sessions of psychotherapy.

On the second day of the treatment, we noticed that the symptoms of vomiting and épigastric pain were disappearing and one month later the endoscopic lesion were also disappearing. Thereafter, the control of the eradication of Helicobacter pylori by endoscopic urease test was negative.

\section{Discussion}

The large-ply nipples gastritis was described in 1947 by Albot et al. [1], and then Moutier et al. [3] made a morphological description of the hypertrophy of gastric folds and nodular areas, sometimes inverted, called "suction cups" "Octopus". Known as Varioliformis gastritis (or sometimes canker or erosive) [3]. The lesion were diffused but predominated at the fundus level. Suspected causal factors were the seizure of anti-inflammatory drugs such as aspirin, indomethacin, Salazopyrin, Phenylbutazone [1] [2].

Immuno-histochemical and clinical studies have shown that this form of gastritis may have an allergic basis [1].

Varioliformis Gastritis is a pathology of the young adult, having an atopic history or consuming continuous anti-inflammatory drugs. Some observations were conducted on female gender children group age 10 and 14 with atopic predispositions [3] [4] [5]. 
In our observation, the female patient of 16 years old, allergic to nickel and having consumed a significant amount of NSAIDs. The massive consumption of NSAIDs for suicidal purposes did not cause exuding or hemorrhagic lesion of the gastric mucosa after performing the endoscopy within 6 hours of consumption.

Varioliformis gastritis is commonly seen in the den, it is diffused only when it reaches the lair, body and fundus of the stomach [1]. That is the case with our observation.

Cut et al. reported that in the child the lesion are less affected by the den but predominated at the level of the fundus and the body of the stomach [5].

In addition to this, sometimes severe acute manifestations, lymphocytic gastritis may have been associated with malignant diseases (lymphoma or gastric carcinoma) [3].

Several research reported that during Varioliformis gastritis a lymphocyte in the epithelium infiltration is noted, hence the name of lymphocytic gastritis [1] [2] [3], but not all lymphocyte gastritis are Varioliformis [6]. We have noticed lesion of chronic gastritis with diffuse inflammatory infiltrates made of lymphocytes and plasma with the presence of Helicobacter pylori.

Very little was know about ethiopatogenesis of gastritis varioliform lesions. Malfertheiner et al. reported that the Helicobacter pylori infection was $89 \%$ among 37 patients with gastritis varioliform lesion. Helicobacter pylori infection thought to be the promoter [7].

The causal role of Helicobacter pylori is more than likely in some lymphocyte gastritis in relation to an immune response occurring in some patients sensitized to the microbial antigen [3].

An immuno-allergic hypothesis was particularly defended in the 1980's by Lambert et al., who already evoked an allergic origin before a cluster of suggestive clinical, biological and experimental arguments. André and al had established in 1985 [8] from a sample of 100 adult patients a first list of foods as cause of their allergy. Since then, the list had been extended with many more products. In addition to some exotic fruits, spices and peanuts are at the forefront, and also sulphites containing in many foods and medicines, as preservative [2].

All these arguments are still not sufficient to prove an allergy, which alone can do the reintroduction test of the allergen with the risks inherent in systemic manifestations.

Also, the frequent association of lymphocytic gastritis with celiac disease brings additional arguments to the immune mechanism of the disease. In both cases, lymphocyte infiltration of the epithelium is found [2], but no immuno allergic investigation was carried out in our observation.

\section{Conclusion}

The consumption of non-steroidal anti-inflammatory drugs in massive quantity may or not be the only main cause for exuding and hemorrhagic lesion, also for gastropathies varioliformis especially when it is an atopic field. The search for 
Helicobacter pylori do it is systematic in order to eradicate.

\section{References}

[1] Caporali, R. and Luciano, S. (1986) Diffuse Varioliform Gastritis in a 10 Year Old Girl Is Reported. Archives of Disease in Childhood, 61, 405-407. https://doi.org/10.1136/adc.61.4.405

[2] Andre, C., Gillon, J., Mouliner, B., Martin, A. and Fargier, M.C. (1982) Randomised Placebo-Controlled Double-Blind Trial of Two Dosages of Sodium Cromoglycate in Treatment of Varioliform Gastritis: Comparison with Cimetidine. Gut, 23, 348-352. https://doi.org/10.1136/gut.23.4.348

[3] Bernard, P., Friedel, J., Diebold, M.D., et al. (2002) Lymphocytic Varioliformis Gastritis: Seek the Allergen! Hepato-Gastro et Oncologie Digestive, 9, 225-229.

[4] Dohil, R., Hassal, E., Jevon, G. and Dimmick, J. (1999) Gastritis and Gastropathy of Childhood. Journal of Pediatric, 29, 378-394.

[5] Couper, R., Laski, B., Stringer, D. and Durie, P. (1989) Chronic. Varioliform Gastritis in Childhood. Journal of Pediatrics, 115, 441-444.

https://doi.org/10.1016/S0022-3476(89)80852-2

[6] André, C., Moulinier, B., Lambert, R. and Bugnon, B. (1976) Gastritis Varioliforme, Allergy and Disodium Cromoglycate. Lancet, 1, 964-965.

https://doi.org/10.1016/S0140-6736(76)92744-6

[7] Zou, T.-H., Zheng, R.-H., Gao, Q.-Y., et al. (2016) Factors Affecting Occurrence of Gastric Varioliform Lesions: A Case-Control Study. World Journal of Gastroenterology, 22, 5228-5236. https://doi.org/10.3748/wjg.v22.i22.5228

[8] André, C. and Colin, L. (1985) Food Allergy. Immunologie Médicale, 10, 21-26. 